\title{
Revealing residents' shared values through crowdsourced photography: Experimental approach in participatory urban regeneration
}

\begin{abstract}
Many cities in the developed world face a need for a regeneration of the aged-up urban quarters. Typical examples are the modernist urban neighbourhoods built in European cities after World War II. At the time of their construction, they represented new living standards but need to be regenerated to be able to cope with the needs and expectations of contemporary residents. These expectations largely depend on the residents' own perceptions and evaluations of the state of the art of their living environments. This paper presents an experimental approach to revealing such perceptions. The approach is based on crowdsourced analytical photography and attached descriptions. It was initially developed as a part of the EU project Human Cities to offer citizens of Ljubljana a tool to express their concerns about their living environments. It is focused on revealing shared values of local communities, which are seen as a starting point for setting up participatory urban regeneration strategies.
\end{abstract}

Keywords: participatory urban design, public space, urban regeneration, residents, shared values, photography

\section{Introduction}

European cities which grew very quickly after the Second World War are faced with a pressing need for urban regeneration of the then new urban quarters. This does not apply solely to abandoned industrial areas but also to the large housing estates that were built to accommodate the workforce. These residential areas are in a need of improvement of urban living conditions in order to be competitive and meet the expectations of contemporary urban dwellers. Residents' notions and expectations will therefore be considered as an important input in preparing participatory regeneration strategies. They are closely related to cultural norms and values and can greatly influence one's notion of (di)satisfaction with the living environments (Križnik, 2018) as well as one's willingness to take on a role of an active citizen in the regeneration process (Dargan, 2009; Denters and Klok, 2010).

Renowned urban anthropologist Lisa Redfield Peattie (1998) points out the importance of common values in communities. She argues that the values of community are of equal or even bigger importance for our happiness than material standards of living. Her observations have been informed by numerous peace actions related to urban planning that sought social change by inclusion of all interests and groups in the planning processes. This is a reminder of the importance of understanding a community's experience with its living environments. In order to do so, it is essential to reveal people's perceptions of their living environments (Sarason, 1974 and 1986; Chavis and Pretty, 1999).

Knowledge of the shared common values of residents of urban environments is important for setting up common visions of the future. Once the collective values of a local community have 
been identified, they can be transformed into the backbone for the bottom-up action plans of community improvements with the active participation and involvement of the inhabitants. As Medved observes in his comparative study of various approaches to top-down and bottom-up urban regeneration "the sustainable neighbourhoods implemented with the participatory bottom-up approach generate stronger local governance systems and are more socially sustainable" (Medved, 2017: 120).

Shared visions for future developments are especially important in the field of urban public spaces as these common spaces aim to address the needs of people from all walks of life. The new approaches to participatory redesign of public space have been the focus of the European project Human Cities that has been running in eleven cities under the Creative Europe programme from 2014 to 2018 (www.humancities.eu). Its main objective was development and testing of new approaches to participatory urban regeneration through experimentation in public space with the participation of residents. One of the experiential urban areas was in the north of Ljubljana, the mid-sized capital city of Slovenia with about 280.000 inhabitants. Ljubljana has a rather large number of aging large-scale housing estates that need comprehensive approach to urban renewal (Regional Development Agency of the Ljubljana Urban Region, 2013; City of Ljubljana, 2014). The city does not possess a strong tradition of bottom-up urban planning. Public participation is largely dealt with in a superficial manner within the formal planning procedures (Nikšič, 2014). The Human Cities experimentation thus tested possible alternative approaches that would help the local residents to have their say in the matter.

The main objective was to develop a new tool that would reveal inhabitants' values in relation to their living environments. However, since the perception of space is subject to constant change, revealing the values of the users of urban space can become a theoretical and practical challenge (Walter, 1988; Thwaites \& Simkins, 2007; Nikšič, 2008; Nikšič \& Butina, 2017). The following topics have been highlighted within the theoretical framework:

- How to reveal the common values of the local community in relation to its living environments?

- Should established methodologies (interviewing, perceptual mapping, cognitive mapping, etc.) be upgraded/combined with new technologies and/or social networking media? What is the general usefulness and real value of crowdsourced information in revealing people's attitudes towards their living environments?

- How to track changes in the value systems and how to integrate them into the urban regeneration process? What kind of urban design solutions are robust enough to stand the changing nature of value systems over time?

These complex issues have been addressed in different ways. This paper will focus on one single approach that aims to develop an innovative tool based on the use of new technologies to reveal residents' shared values as a part of urban regeneration process. It is based on the new forms of communication used in contemporary society in which photography and short texts play an important role.

\section{The image and its caption - theoretical background}

Kress and van Leeuwen (2006) introduced the concept of photostory as a composition of images and descriptions which form semiotic codes. This forms a multimodal message where images and captions are in an interaction and develop their relation to form a sign. The interpretation of a particular sign depends on both the creator and the reader and is strongly culturally conditioned (Barthes, 1977). Mitchell (2009) argues that the act of reading does not only refer 
to the reading of a text, but also of everything that surrounds us, including the signs and phenomena, therefore the receiver of the message can be called the reader. When the image and the word meet in the multimodal message, the reading approach is different from the classical reading. The reader has to set up the meaning (Tominc, 2016). This process depends on the reader's experiences and knowledge, trust in the source of the message, and the influence of social environment. Eco (1979) introduced the term "ideal reader" to stress that the reader is the one that concludes the process of passing the (in this case image creator's) message to the others - the reader is called ideal as he/she is awaked and aware of the existence of numerous interpretations of the image.

The image and the word are involved in a dynamic process and represent two different ways of visual communication - non-verbal and verbal. A combination of both represents one of the most powerful communication strategies (Kress, 2004; Lester, 2006). The image is an effective way to transfer knowledge and information. Muhovič (1998) points out that images facilitate the flow between empiricism and theory, and increase flexibility when operating with the experience. Using imagery encourages the reader to think and communicate; it motivates him to take a different view. This is an important aspect for the participatory urban planning, too, if we imagine a citizen as an image creator and the urban planner as an image reader. The image generated by a citizen can offer to the planner a new insight into the citizens' perceptions and interpretations of the environments.

The advantage and communicative power of the image lie in the fact that it can be used on a small area to display a large amount of information that would require much more space if expressed in verbal form. Collection of images is also less time-costly than classical participatory procedures, since they can be crowdsourced by using ICT (See et al., 2016). Due to the numerous possible interpretations of the images, however, the interpretation of the photography-based crowdsourced data seems to be more demanding, therefore the usage of residents-generated photography as a communication channel between the residents and planners in participatory procedures needs to have a firmer framework in order to bring useful information into the planning process.

The images show data at several levels, from a wide view to the fine detail (Tominc, 2016). Decoding the meaning of the image does not require knowledge of writing and understanding of language, as is true for the text, but it does require knowledge of visual language and symbolism (Mancini, 2011), which would not necessarily be a skill of an urban planner. Barthes (1977) points out that the image can easily be detected, while decoding is less straightforward as it can lead to different interpretations, which is especially true for the images without captions. Barthes (1977) also argues that we rarely see the image without a caption, even if it is only the subtitle that denotates very basic information, such as time and location. For Barthes, the importance of the image is always associated with and depending on text, as images by themselves are too polysemic and too open to different interpretations. In his opinion, we need words that supply the image with a definitive meaning. The text accompanying the image can assist in narrowing down the wide spectrum of possible interpretations.

Therefore, in order for the resident-generated image to be useful in the participatory planning process, it needs to be accompanied by a text in the form of captions. There are several reasons for this. It could be that the image is very ambiguous and vague, so its contents cannot be clearly defined. Words can more accurately and clearly explain the content of the image. Captions are essential if we want to make the reader clearly understand the message. Starc (2009) argues that it is sometimes enough to decode the image by a couple of words only, but even if few, they 
are indispensable. Another way to avoid the ambiguity is to ask the image producers to link their images with appropriate tags that have been pre-set by the foreseen image reader. This helps to avoid misunderstandings and to set up the common understanding between the producer and the receiver of the message (Fischer, 2011), which is an essential pre-condition for a successful communication between the many actors in the participatory planning processes.

\section{Revealing shared values of local community through photography, captions and tags}

The theoretical insight into the capacity of photography as a communication tool in participatory processes between the residents on one side and the planners on the other has shown that photography in itself is too polysemic and too open to various interpretations to be used on its own. On the other hand, photography has become a part of everyday social communication and thus form of media, accepted by and practiced among widest public (Zappavigna, 2016; Guerrero et al., 2016). Therefore, it is well-worth experimenting with the other compatible types of information that could supplement photography and turn it into a possible communication channel between the residents and the planners.

With this in mind, we developed a tool called Photostory of our neighbourhood - PON (Sln.: Fotozgodba naše soseske). In a broader sense, this is a photo contest in the form of a crowdsourced on-line photo album which offers an insight into the current state of the art of living environments, as seen and interpreted by the inhabitants themselves. The album is created by residents and visitors of urban neighbourhoods, thus illustrating the local urban environments and their life through the eyes of the people living or occasionally spending time in such locations.

The Photostory had three main missions. First, to invite citizens to start observing and thinking about their local environments, their assets and problems, and to thus become more conscious of the characteristics of the spaces they inhabit. Secondly, to reveal the citizens' perceptions and interpretations of living environments to urban planners, who often lack this layer of information and thus fail to implement it in their planning strategies. And thirdly, to elicit inhabitants' thinking of their possibly more active role in participatory urban regeneration processes as active citizens with their own contributions, based on their own observations of the living environments and their possible improvements.

Five main thematic categories were set up by the project team to remind the residents of some important aspects of urban life, as well as put attention to some important urban design principles that impact the quality of life in the city. They were described in the form of some lead questions, as shown in Table 1. 
Table 1: Five thematic categories of Photostory of our neighbourhood (PON).

\begin{abstract}
Most pleasant place in my neighbourhood
We usually spend a major part of our time in our neighbourhood, therefore its arrangements importantly influence the quality of our life. Which are the spaces in the neighbourhood that I like, find interesting and like to spend time in? What makes them pleasant? Activities and people that spend time there, street furniture, presence of natural elements, maybe the light and colours or details on the surrounding buildings? Try to show the places of your neighbourhood that you find pleasant, and explain what makes them attractive, through the photo and its caption.

\section{Professions in my neighbourhood}

Good neighbourhoods are not merely sleeping spaces, but places where different activities and programs take place that cater to the needs of inhabitants of the neighbourhood and the city. The baker at the street corner, the sales person in a local shop, the driver of a bus that stops in the neighbourhood, the local greens care-taker, etc., are only a few more visible professions which importantly contribute to the quality of life in a neighbourhood. At the same time, there are many other professions that are more hidden to our eyes - people with different skills, abilities and knowledge. Present their activities through a photo and its caption.
\end{abstract}

\begin{abstract}
My neighbour
Fast rhythm of life and new ways of communication, supported by new communication technologies, are changing and often weakening contacts between people living in the same space. With the help of a photo and its caption catch the moments showing that neighbourhoods are inhabited by social beings who, despite changed ways of life, still gather together, support and help each other. Street play, chatting on a bench in a local park or ringing a neighbour's door because you have run out of flour while baking biscuits: these are all examples of activities that join people in a neighbourhood. Photos with captions in this category should show that lively neighbourhoods are inhabited by people who make good neighbours, instead of complete strangers to each other.
\end{abstract}

\title{
Borders of my neighbourhood
}

Where does my neighbourhood spread to? What are its borders and what defines them? Are they physically, functionally or symbolically defined? Borders may sometimes be clear and exact, sometimes blurred and fluid. Getting to know the borders is helpful to someone who tries to reach beyond them. Or strengthen the distinctive identity of the space within. Present the borders of your neighbourhood with the help of a photo and its caption.

\section{Shared values in my neighbourhood}

Which are the values, shared by the inhabitants of my neighbourhood? Which ideals unite us as a community? How are they reflected in space? And can they be a basis for common action of inhabitants trying to improve the living conditions in a neighbourhood? Values are an immaterial category, but are nevertheless often reflected in the physical, real environment. This category collects photos that show the state of the art of the neighbourhoods, reflecting the values of their inhabitants.

Upon the contribution of their entries to PON, the residents were asked to submit three types of information with each entry: photo as the main information, supplemented by its caption and the selection of any number of tags from a predefined list. The photo and its caption aimed to reflect residents' own observations and notions about their living environments. Meanwhile, the pre-set tags addressed certain particular issues that are of particular interest to the planners. In other words, the list of tags provides the urban planners with an entry point into residents' attitudes, so that a definitive aspect that matters in urban planning terms could be established. To go beyond the existing planning practices, in the scope of the Human Cities project, thirteen shared values were identified, as shown in Table 2 . They were gathered through review of more than 170 civil initiatives reclaiming public spaces across Europe (Human Cities, 2018). 
Table 2: Human Cities Shared Values (HCSV).

\begin{tabular}{|c|c|}
\hline $\begin{array}{l}\text { Shared } \\
\text { Value }\end{array}$ & Definition \\
\hline Empathy & $\begin{array}{l}\text { The ability to understand and share the feelings of others, despite different backgrounds and } \\
\text { life experiences. Empathy creates a bond between individuals that ends up becoming part of } \\
\text { their shared identity. }\end{array}$ \\
\hline Wellbeing & $\begin{array}{l}\text { A state of feeling healthy and happy. It is a contribution to society through knowledge, } \\
\text { culture, design, music, ecology, healthy food or renovation of public spaces. The main goal of } \\
\text { wellbeing is to improve living conditions so that people can achieve better physical and } \\
\text { mental health. }\end{array}$ \\
\hline Sustainability & $\begin{array}{l}\text { Sustainability is concerned with meeting the needs of current population without } \\
\text { compromising those of future generations. It includes environmental, social and economic } \\
\text { aspects. }\end{array}$ \\
\hline Intimacy & The possibility of feeling a sense of closeness with people, objects or places. \\
\hline Conviviality & $\begin{array}{l}\text { Live together, share ideas, activities, discussions... Create a common spirit, a sense of } \\
\text { belonging around which people can gather and find meaningful. }\end{array}$ \\
\hline Mobility & The capacity to make citizens leave their private spaces for public ones. \\
\hline Accessibility & Being open to everyone and easily reachable. It has both geographic and social meaning. \\
\hline Imagination & $\begin{array}{l}\text { The ability of mind to be creative with new images, ideas, concepts, and the like. Imagination } \\
\text { is the main provider of images and dreams of new solutions to our daily problems. }\end{array}$ \\
\hline Leisure & $\begin{array}{l}\text { Free time, away from demands of work and duty, when one can rest, take it easy and enjoy } \\
\text { hobbies or sports. }\end{array}$ \\
\hline Aesthetics & $\begin{array}{l}\text { A visual attribute aiming at beauty, creativity and innovation, which provides an identity to a } \\
\text { place. }\end{array}$ \\
\hline Sensoriality & The mobilization of a person's senses, whether hearing, seeing, tasting, smelling or touching. \\
\hline Solidarity & Solidarity is a unity of people sharing the same interests in order to help each other. \\
\hline Respect & $\begin{array}{l}\text { Respect is showing due regard to people's lives, opinions, wishes and rights. It implies there } \\
\text { are no barriers or stereotypes that come between us. }\end{array}$ \\
\hline
\end{tabular}

PON is "written" by the residents themselves and thus reveals their own notions of their living environments, as well as their personal values in relation to these environments. Any registered visitor to the web page can submit up to 10 photos, each with attached caption and any number of tags reflecting HCSV. A database that has been formed in this way allows urban planners to get an insight into the concrete places and their characteristics that matter to the local residents in general, and the values that characterize these places through the opinion of the residents in particular. These shared values can become an important stepping stone in preparing shared visions and plans for urban regeneration which would be adopted by the residents and thus more likely implemented with their active participation.

The next section reports the results of the first launch of PON in the 2016-2017 period. It is focused on the analyses of the shared values that were revealed through the photo contest.

\section{The results of the first launch of Photostory of our neighbourhood}

PON was launched for the first time in autumn 2016 and promoted via website and other infochannels of UIRS and affiliated partners, among others an exhibition held at the Museum of Architecture and Design that presented the legacy of neighbourhoods built in socialist times. This exhibition represented a good momentum and opportunity to encourage the inhabitants to rethink the questions of the qualities of large scale housing estates, as well as open a discussion on maintenance and participatory urban regeneration procedures. 
PON was organized as a competition with prizes to attract a large number of residents. The main prize was the exhibition of the winning entries at the travelling European Human Cities exhibition on display in eleven European cities, as well as a print of winning photos in the form of postcards (Nikšič et al, 2017). To select the winners, an interdisciplinary international jury was set up, composed of professionals from the fields of architecture, art history, exhibition design, geography, social innovation, urban design and urban planning. The jury selected five winning photos in each of the five thematic categories.

Altogether, 172 entries were submitted (see some examples in Figures 1-5). Ten were submitted without all relevant information (with either caption or attached shared values missing), so 162 entries could be taken into account and analysed.

The collected data offered a wide range of insights that would usually not be accessible to the urban planners:

- It was possible to identify parts of the neighbourhood that most evoked the residents' perceptions (i.e., where most of the photos had been taken). The planners were thus enabled to perform an in-depth study of these places to understand why local people strongly associated with them. Captions to the photos proved to be very helpful in revealing this aspect.

- The distribution of all photos among the five thematic categories showed which of the thematic issues that the planners pre-defined as important for developing the common regeneration strategies were most relevant to the residents.

- The in-depth analysis of the motives that appeared on the photos revealed answers to several questions: the importance of built and natural features in the residents' perceptions, the importance their users gave to the local environments, the relations between the environments and their users in the eyes of the residents, the role of urban design and architectural details in forming the character of the neighbourhood, etc.

- The analysis of the captions revealed most common words and phrases that, in the residents' opinions, characterize the neighbourhood.

- The most often selected shared values revealed possible foundations on which joint actions of the local community could be based in the participatory regeneration endeavours.

The shared values of the inhabitants were central to experimentation and therefore studied into more detail. The material was looked upon from two different angles. First, the most/least often indicated shared values, regardless of their position at the first, second or third place, were identified. Secondly, the most/least often indicated shared values within the range (within the values that were named in the first place, second place, etc.) were revealed. All eligible material, submitted to the contest, was analysed in this fashion. In order to compare the points of view of the participants and the jury, the 25 winning images and their captions were analysed in the same way.

\subsection{Shared values indicated in the crowdsourced materials}

The most often mentioned value (with any ranking - first, second or third place - taken into account) was wellbeing (60x), followed by leisure $(48 x)$, aesthetics $(44 x)$, conviviality $(43 x)$ and imagination $(42 x)$. The ranking of other categories was as follows: empathy (36x), intimacy $(33 x)$, sensoriality $(33 x)$, sustainability $(32 x)$, respect (30x), accessibility $(25 x)$, mobility (20x) and solidarity $(10 \mathrm{x})$. 
When the number of recalls within each of the five competition categories is taken into account, the results are a bit different. In the category Most pleasant place in my neighbourhood, wellbeing $(27 x)$ and leisure $(23 x)$ were indicated most often, followed by aesthetics and sustainability $(23 x)$. The least often indicated values were mobility $(1 x)$, solidarity $(2 x)$ and accessibility $(4 x)$. In the category Professions in my neighbourhood, the most often indicated shared values were sustainability $(9 x)$, conviviality $(8 x)$ and respect $(8 x)$, while intimacy was indicated most rarely (2x). In the category My neighbour, none of the shared values stood out, since they were all more or less indicated the same number of times. Solidarity was the only shared value that did not get any vote. In the category Borders of my neighbourhood, the two most often indicated shared values were aesthetics (18x) and sensoriality (17x). Solidarity was again the least often mentioned value (1x). Meanwhile, in the category Shared values, leisure $(15 \mathrm{x})$ and wellbeing $(12 \mathrm{x})$ were indicated the most often, and aesthetics $(1 \mathrm{x})$, sensoriality $(2 \mathrm{x})$ and solidarity $(4 \mathrm{x})$ the least often.

When considering the importance of each value to the participant (first, second or third place on the list of three values that describe the submitted photo best), it becomes clear that in all categories wellbeing got the most attention (53x), followed by empathy (35x) and sustainability $(25 \mathrm{x})$. Four shared values were never indicated as most important ones, and never made it into the first place: leisure, respect, sensoriality and solidarity. The values most often named at the second place were conviviality (27x), aesthetics (18x) and imagination (17x). Values that most often made the third place were leisure (36x), respect (30x) and sensoriality (26x).

\subsection{Shared values indicated in the jury's selection of crowdsourced materials}

For a comparison between the notion of the residents on one hand and the professionals on the other the same analyses were performed for the 25 winning photos chosen by the jury. The strongest value (first, second or third place) was conviviality (13x), followed by leisure $(9 x)$, while solidarity ended up last $(1 \mathrm{x})$.

Once more, when the number of recalls within each of the five competition categories is taken into consideration, the results are a bit different. In the category Most pleasant place in my neighbourhood, most often accessibility, intimacy, conviviality and leisure were indicated (all of them 3x). In the category Professions in my neighbourhood, the most often indicated shared values were wellbeing, conviviality and respect (all of them 3x). In the category My neighbour, it is mobility that stands out (6x). In the category Borders of my neighbourhood, the most often indicated shared value was wellbeing $(3 x)$, followed by intimacy, sustainability, accessibility and imagination $(2 \mathrm{x})$. Meanwhile, conviviality was indicated most often $(4 \mathrm{x})$ in the category Shared values.

When considering the importance of each value to the participant (first, second or third place on the list of the three values that describe the submitted photo best), the jury's results differ from those of the participants. In all categories wellbeing is the strongest one (9x), followed by sustainability and conviviality $(5 \mathrm{x})$. The value most often named at the second place is conviviality $(8 x)$, while leisure takes the third-place $(7 x)$. These two values (most often named at the second and third place) overlap with the original indications made by the participants. 


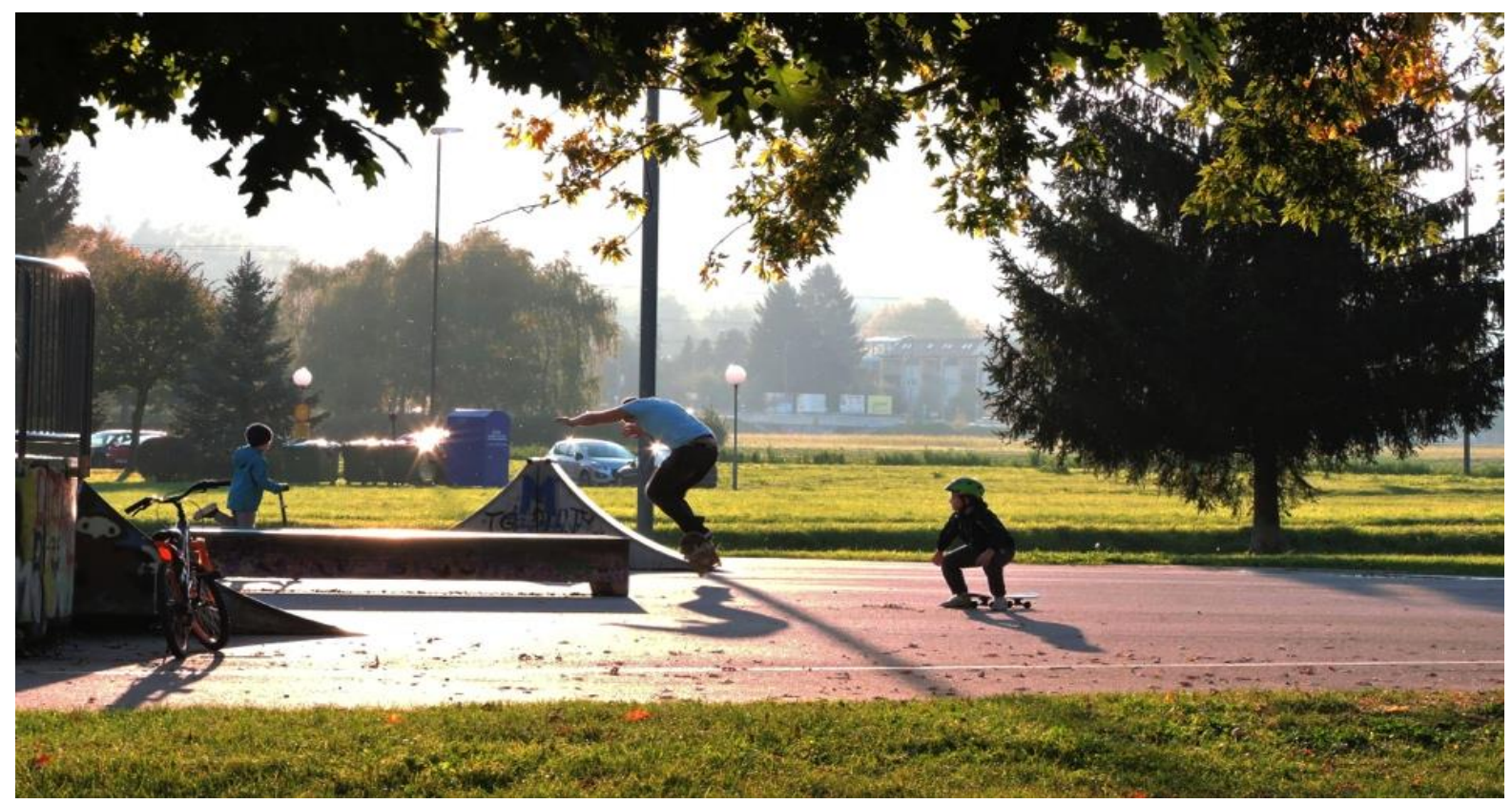

Figure 1: Photo submitted to category The nicest place of my neighbourhood: In a small corner at the edge of the neighbourhood there is a secret place where the whole community gathers, from mothers with babies to competitive youths, to grandmothers who observe their growing grandchildren with an invisible pride. Attached shared values: conviviality, imagination, leisure (author: Urška Podgrajšek).

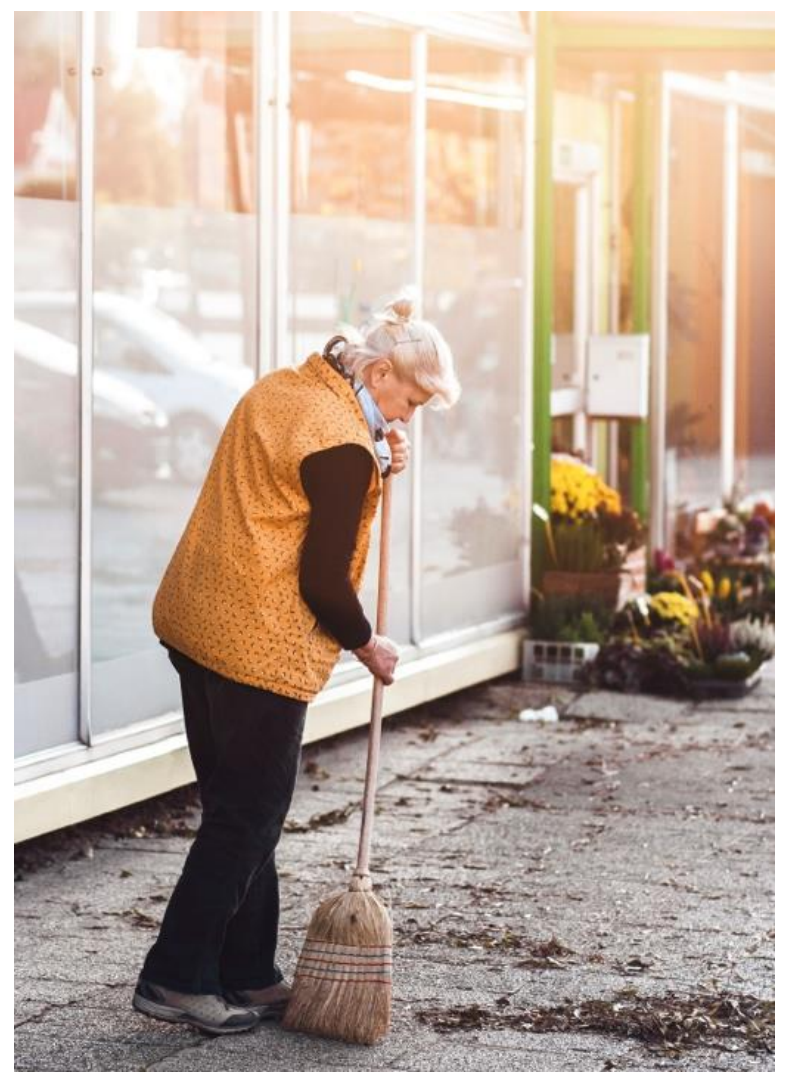

Figure 2: Photo submitted to category Professions in my neighbourhood: Not so long ago, a small centre for the elderly, meant for socializing, exercise and other activities, was opened in our neighbourhood. The lady in the photo was just sweeping autumn leaves in front of the entrance. Attached shared values: wellbeing, leisure, respect (author: Lea Piškur). 


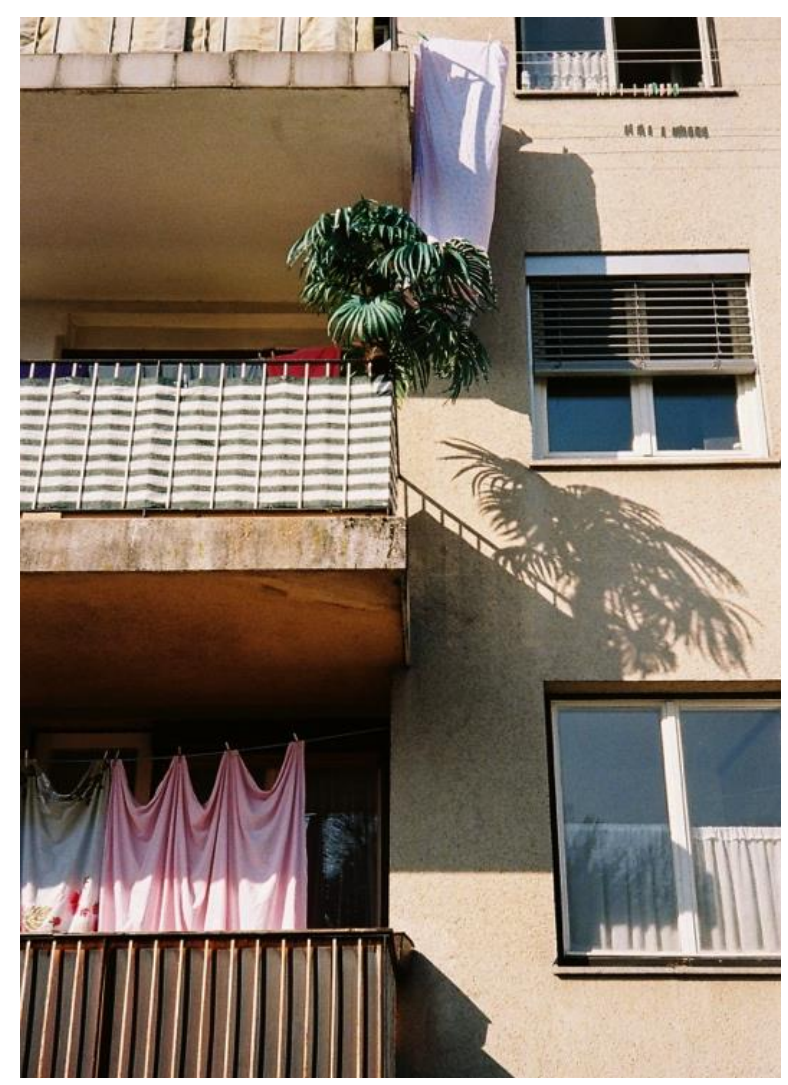

Figure 3: Photo submitted to category My neighbour: Balcony tales 2015. Attached shared values: conviviality, imagination, aesthetics (author: Maruša Račič).

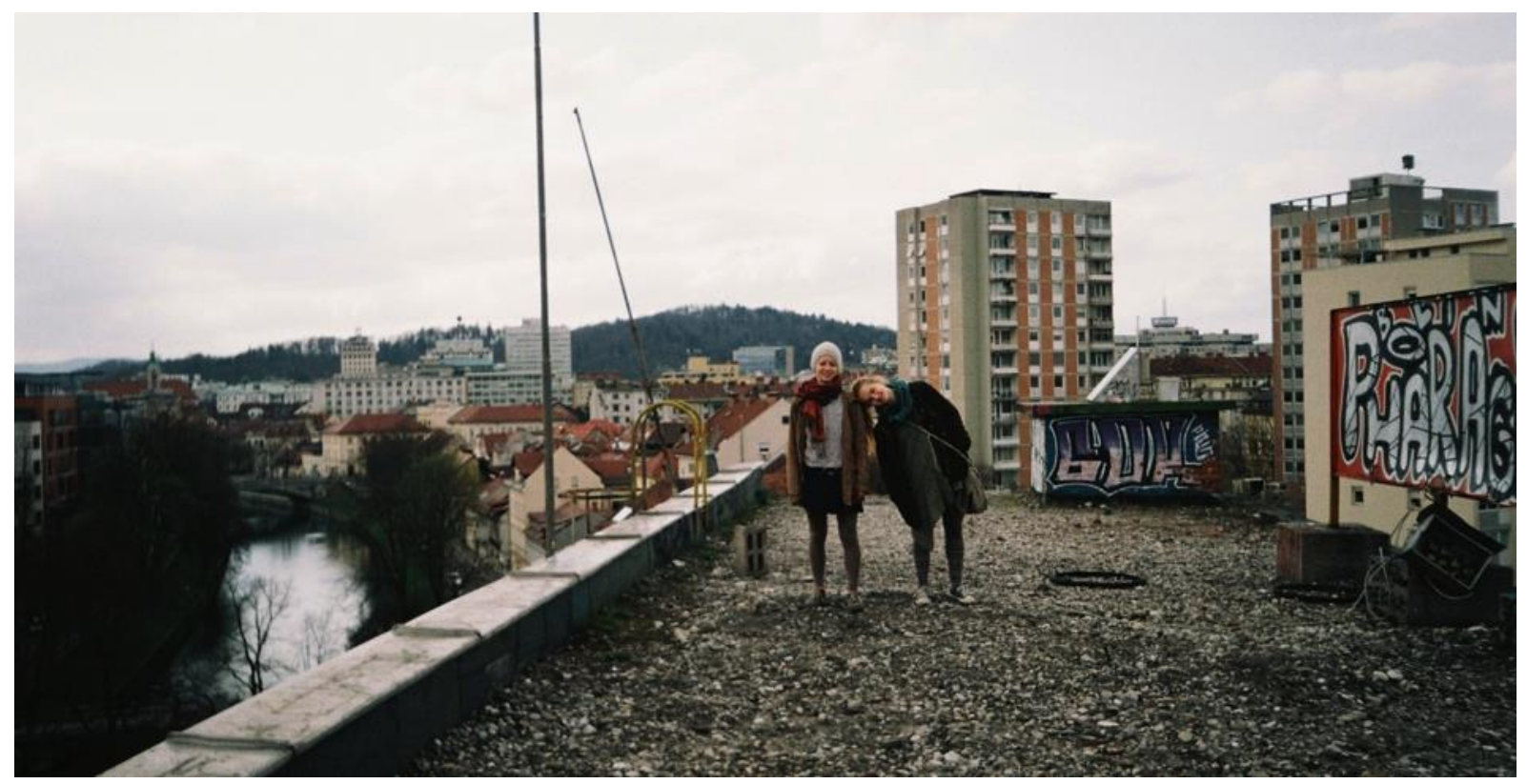

Figure 4: Photo submitted to category Borders of my neighbourhood: The border of my city is the horizon; when I surpass it, the sky becomes the limit. Attached shared values: wellbeing, accessibility, imagination (author: Tisa Neža Herlec). 


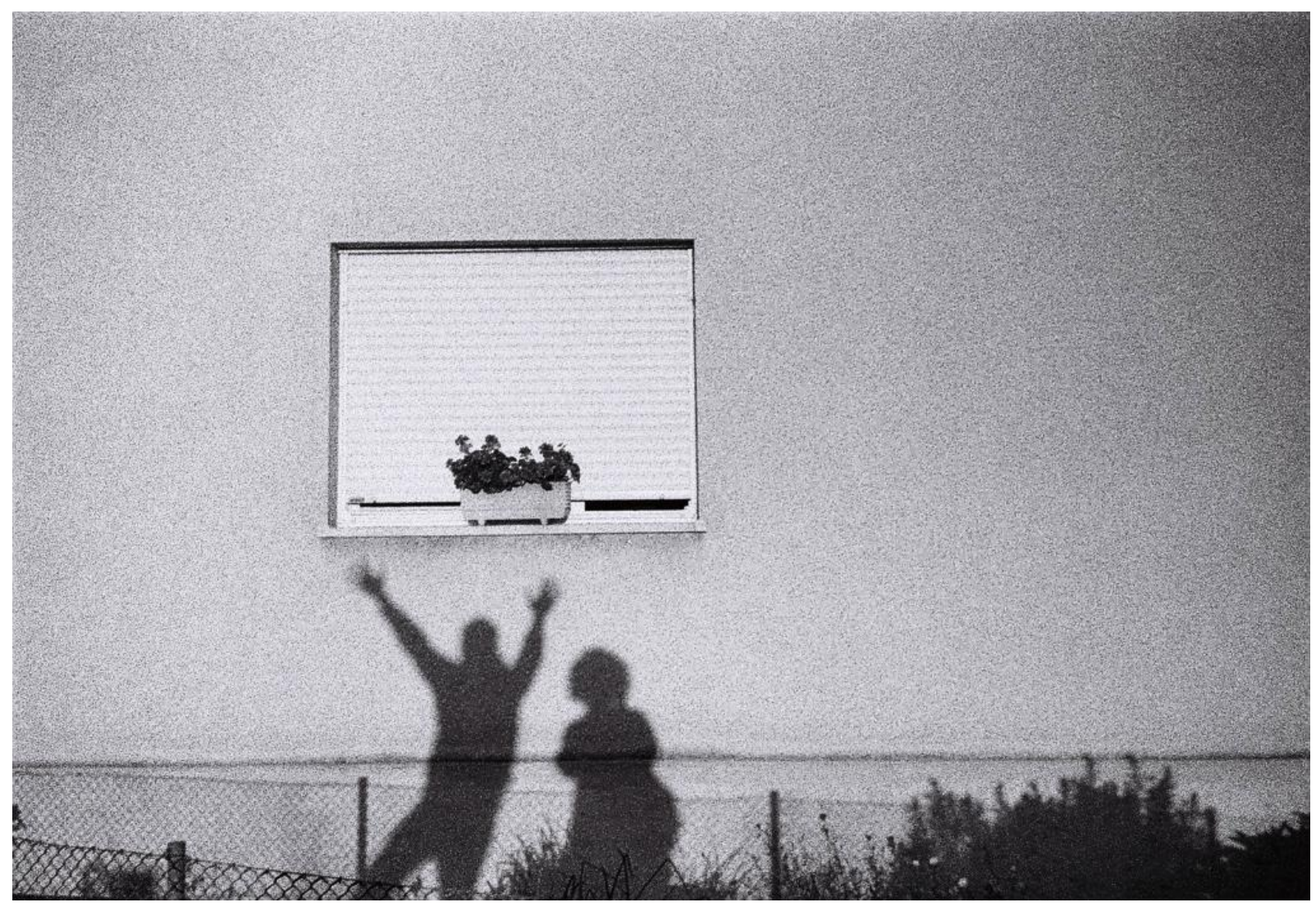

Figure 5: Photo submitted to catgory Shared values of my neighbourhood: My childhood friend and I, we are but shadows, just memories in the neighbourhood where we grew up. We return sometimes and recall our memories. Attached shared values: conviviality, imagination, leisure (author: Tisa Neža Herlec).

\section{Photostory as a tool that reveals residents' perceptions of living environments}

The PON experiment showed the potential of revealing residents' shared values through crowdsourced photography with captions. The high response from the residents indicates that this is a tool contemporary urban dwellers can embrace as a channel of communication with planning professionals and authorities. However, such a tool challenges the planners to take a different view and puts them into a new role that may test their current abilities. To be capable to receive the messages communicated by the residents and become, as Eco (1979) put it, "the ideal readers", such a tool has to be put within a strong and pre-defined framework, linking the residents' free expressions to the urban planning objectives and frameworks. PON experimented with thematic categories and tags that were both pre-defined by planning professionals and attached to the submitted materials by residents. These pre-defined categories proved to be successful in translating residents' messages more directly into the urban planning issues.

PON in Ljubljana was based on public spaces as its main theme, a theme that any resident encounters in his/her daily routines. Public space as a common space proved to be a good ground to reveal place attachments and identifications with places. The high number of participants in the contest indicates that residents are ready to contribute to the urban regeneration processes in new, previously unseen ways, provided that the core theme (public space) and communication channel (photos with captions) are appropriately set. Urban planning professions should build on such good examples and develop new well-structured tools to encourage truly participatory involvement of residents and their notions in regeneration 
processes in the locally adapted manners. Such tools must not stay at the level of the commonly prevailing social media practices but should be adjusted to the numerous and specific demands and reflect the concrete communities and their environments, while embedded in the complex process of urban regeneration within systems of planning. As PON indicated, certain predefined categories and tags can serve as the common ground in order to avoid misunderstandings between producers and receivers of the messages. At the same time, such tools must stay simple and straightforward to use in order not to discourage potential users.

One practical question that stays open is the integration of data, gathered in these new innovative ways, into the existent planning procedures. As cities are getting more dynamic, traditional master plans are becoming less appropriate for the management of the (re)urbanization processes and must be upgraded with new tools. However, despite the existence of certain new tools and approaches, their integration into official planning procedures is lagging behind. This is an issue that must be more thoroughly dealt with in the future.

The experiment with the Photostory of our neighbourhood also shows how subjective the spatial perception is and how it changes through times, reflecting the spirit of current social reality. The 2016 experiment revealed that values such as well-being, leisure, aesthetics and conviviality are currently the most strongly shared among the local residents, while some others, such as solidarity, that were much stressed in the previous socio-economic framework of socialism, end up much lower on the ranking lists. These results remind the professionals that they must not in any sense automatically assume the residents' notions about their own living environments.

The Photostory also opened a number of completely new perspectives of positive aspects of living in suburban neighbourhoods, even if such environments are rather aging. These new perspectives of the neighbourhoods can not only help to strengthen their identity and increase the self-esteem of the residents, but also present new opportunities for development of new niches in the local economy, e. g. in the tourist sector by re-directing the tourist flow from central attractions to more peripheral ones, those that would not be recognized without the expertise of local residents. This approach represents a new window of opportunity for "less attractive" urban areas in the cities that often end up on the losing end of the global race for attention of potential visitors and investors.

Matej Nikšič, Urban Planning Institute of the Republic of Slovenia, Ljubljana, Slovenia (matej.niksic@uirs.si)

Biba Tominc, Urban Planning Institute of the Republic of Slovenia, Ljubljana, Slovenia (biba.tominc@uirs.si)

Nina Goršič, Urban Planning Institute of the Republic of Slovenia, Ljubljana, Slovenia (nina.gorsic@uirs.si)

\section{Acknowledgments}

The authors would like to thank all participants who contributed their photostories to the contest in autumn 2016, as well as the partners of Human Cities project (EU Programme Creative Europe 2014-2020), namely the civil initiative Skupaj na ploščad!, the Museum of Architecture and Design and the Faculty of Architecture of the University of Ljubljana. Special thanks for their collaboration go to Lucile Fauviaux and Héloïse Gautier, international trainees at the Urban Planning Institute of the Republic of Slovenia. Thanks go to Igor Bizjak for all of his technical support with PON. This paper was partly made possible with the support of Trans-Domain COST Action TD1408 Interdisciplinarity in research programming and funding cycles (INTREPID) and Target Research Programme Review and analysis of development visions and potentials of Slovenian cities for defining key urban 
development measures, financed by the Slovenian Research Agency and the Ministry of the Environment and Spatial Planning of the Republic of Slovenia.

\section{References}

Barthes, R. (1977) Image, music, ext. London, Fontana Press.

Chavis, D. M. \& Pretty, G. (1999) Sense of community: Advances in measurement and application. Journal of Community Psychology, 27(6), pp. 635-642. DOI: 10.1002/(SICI)1520-6629(199911)27:6<635::AIDJCOP1>3.0.CO;2-F

City of Ljubljana (2014) Statistical Yearbook Ljubljana 2013. Ljubljana.

Dargan, L. (2009) Participation and local urban regeneration: The case of the New Deal for Communities (NDC) in the UK. Journal of regional studies, 43(2), pp. 305-317. DOI: 10.1080/00343400701654244

Denters, B., Klok, P. J. (2010) Rebuilding Roombeek: Patterns of citizen participation in urban governance. Urban Affairs Review, 45 (5), pp. 583-607. DOI: 10.1177/1078087409356756

Eco, U. (1979) The role of the reader: explorations in the semiotics of texts. London, Indiana University Press.

Fischer, G. (2011) Understanding, fostering and supporting cultures of participation. Interactions. 18(3), pp.4253. DOI: $10.1145 / 1962438.1962450$

Guerrero, P., Moller, M. S., Olafsson, A. S., Snizek, B. (2016) Revealing cultural ecosystem services through Instagram images: The potential of social media volunteered geographic information for urban green infrastructure planning and governance. Urban Planning, 1(2), pp. 1-17. DOI: 10.17645/up.v1i2.609

Human Cities (2018) Challenging the city scale. Investigation. Saint-Etienne, Cite du design.

Kress, G. (2004) Reading images: Multimodality, representation and new media. Preparing for the future of knowledge presentation. Paper presented at the IIID: Expert forum for knowledge presentation, Chicago, IL.

Kress, G., van Leeuwen, T. (2006) Reading images: the grammar of visual design. New York, Routledge. DOI: $10.4324 / 9780203619728$

Križnik, B. (2018) Transformation of deprived urban areas and social sustainability: A comparative study of urban regeneration and urban redevelopment in Barcelona and Seoul. Urbani izziv, 29(1), pp. 83-96. DOI: 10.5379/urbani-izziv-en-2018-29-01-003

Lester, P. M. (2000) Visual communication. Images with messages. Belmont, Wadsforth/Thomson Learning.

Mancini, L. (2011) Visualisations of philosophical concepts. Master thesis. Ljubljana, University of Ljubljana, Academy of fine arts and design.

Medved, P. (2017) Leading sustainable neighbourhoods in Europe: Exploring the key principles and processes. Urbani izziv, 28(1), pp. 107-121. DOI: 10.5379/urbani-izziv-en-2017-28-01-003

Mitchell, W. J. T. (2009) Slikovna teorija. Ljubljana, Študentska založba.

Muhovič, J. (1998) Vizualizacija, znanost in znanje. Anthropos, 30(1-3), pp. 42-81.

Nikšič, M. (2008) Connecting urban microambients into recognizable whole: Structure of open urban public space in mental image of users. Doctoral thesis. University of Ljubljana, Faculty of architecture.

Nikšič, M. (2014) Access to quality open public space as an urban sustainability measure. Geographical Locality Studies, 2(1), pp. 284 - 303.

Niksic, M., Butina Watson, G. (2017) Urban public open space in the mental image of users: the elements connecting urban public open spaces in a spatial network. Journal of Urban Design. DOI: 10.1080/13574809.2017.1377066

Nikšič, M., Goršič, N. \& Tominc, B. (eds.) (2017) Human Cities: Challenging the city scale 2014 - 2018; Public spaces for local life: catalogue. Available at http://www.uirs.si/pub/Human_Cities_Catalogue_Ljubljana2017.pdf (accessed: 20 June, 2018).

Peattie, L. R. (1998) Convivial cities. In: Douglass, M. \& Friedmann J. (eds.) Cities for citizens: Planning and the rise of civil society in a global age, pp. 247-253. London, John Wiley.

Regional Development Agency of the Ljubljana Urban Region (2013) Rurbance - Ljubljanska

urbana regija. TS Factsheet. Ljubljana.

Sarason, S. B. (1974) The psychological sense of community: Prospects for a community psychology. San Francisco, Jossey-Bass.

Sarason, S. B. (1986) Commentary: The emergence of a conceptual center. Journal of CommunityPsychology, 14, pp. 405-407. DOI: 10.1002/1520-6629(198610)14:4<405::AID-JCOP2290140409>3.0.CO;2-8

See, L., Mooney, P., Foody, G., Bastin, L., Comber, A., Estima, J. et al. (2016) Crowdsourcing, citizen science or volunteered geographic information?: The current state of crowdsourced geographic information. ISPRS International journal of geo-information, 5(55). DOI: 10.3390/ijgi5050055 
Starc, S. (2009) Večkodnost in zgradba učbeniškega besedila. In: Jelka Vintar (ed.) Razmerja med slikovnimi in besednimi sestavinami sporočil: Zbornik bralnega društva Slovenije, pp. 45-62. Ljubljana, Zavod Republike Slovenije za šolstvo.

Thwaites, K., Simkins, I. (2007) Experiential Landscape. An approach to people, place and space. London, New York, Routledge.

Tominc, B. (2016) Image caption; Visual grammar by Kress and van Leeuwen as a tool for image analysis in multimodal texts. Master thesis. University of Primorska, Faculty of Humanities.

Zappavigna, M. (2016) Social media photography. Constructing subjectivity in Instagram images. Visual Communication, 15(3), pp. 271-292. DOI: 10.1177/1470357216643220

Walter, E. V. (1988) Placeways. A theory of the human environment. North Carolina, Universityof North Carolina Press. 